\title{
CARBON OFFSETTING
}

\& NATURE-BASED SOLUTIONS

TO CLIMATE CHANGE

\section{Cambridge Zero Policy Forum}

Discussion Paper | October 2021

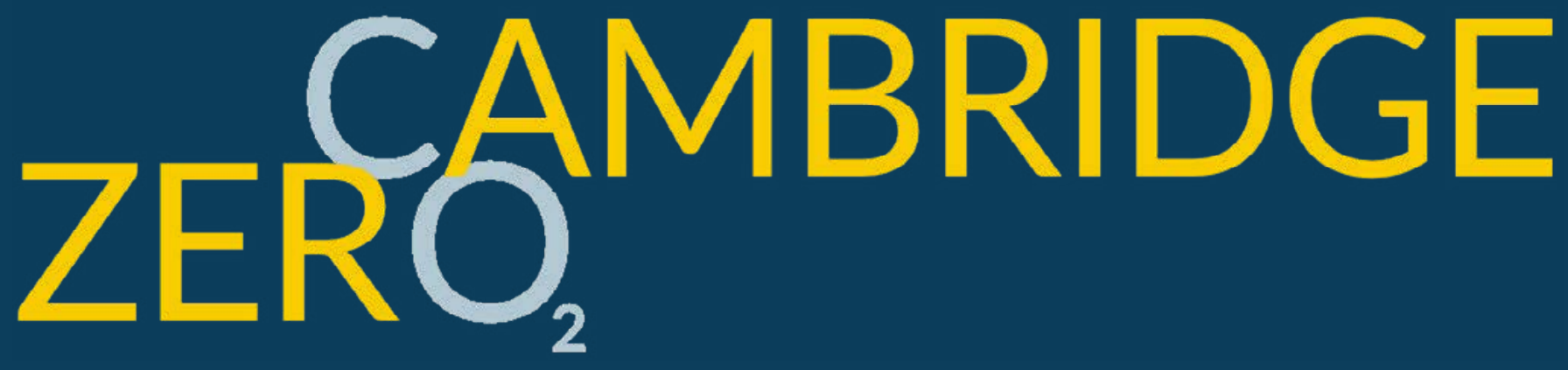




\section{CARBON OFFSETTING \& NATURE-BASED SOLUTIONS TO CLIMATE CHANGE \\ Cambridge Zero Policy Forum}

\section{Discussion Paper | October 2021}

How to cite this paper:

Cambridge Zero Policy Forum (2021) Carbon Offsetting \& Nature-based Solutions to Climate Change. University of Cambridge.

The Cambridge Zero Policy Forum is a multidisciplinary community of academics contributing evidence and expertise to public policies for the transition to a sustainable, inclusive, and resilient net zero society. For more information, please visit:

https://www.csap.cam.ac.uk/Research-Policy-Engagement/cambridge-zero/

Front cover: Mixed landuse forest and agriculture in Bali.

Typesetting and layout: Jen Hayes and Ethan D. Aines 


\section{Contents}

1 Executive Summary $\underline{4}$

2 Introduction $\underline{4}$

3 Nature-based solutions to climate change $\underline{6}$

3.1 Summary of nature-based solutions $\underline{6}$

3.2 Types of nature-based solutions $\quad \underline{7}$

3.2.1 Forests $\underline{7}$

3.2.2 Wetlands $\underline{8}$

3.2.3 Oceans $\underline{8}$

3.2.4 Soil and Agriculture $\underline{8}$

3.3 Co-benefits and externalities $\underline{9}$

4 Carbon offsetting 10

4.1 Summary of carbon offsetting $\quad \underline{10}$

4.2 Key risks associated with carbon offsetting $\quad \underline{12}$

4.2.1 Additionality $\underline{12}$

4.2.2 Carbon leakage $\quad \underline{13}$

4.2.3 Permanence $\quad \underline{13}$

4.2.4 Double counting

4.2.5 Broader ethical concerns

4.2.6 Offsetting and corporate net zero strategies $\quad \underline{14}$

5 Measures that can improve offsetting using nature-based solutions $\underline{15}$

5.1 Policy measures $\quad \underline{15}$

5.1.1 Directly integrating offsetting into government strategy

5.1.2 Investment in technologies $\quad \underline{16}$

5.1.3 Other climate policies $\quad \underline{16}$

5.2 Technological measures $\quad \underline{17}$

5.2.1 Emerging nature-based solutions

5.2.2 Improved measurement, reporting and verification $\underline{17}$

5.2.3 Creating trust in carbon credits $\quad \underline{18}$

5.3 Private sector measures $\quad \underline{19}$

5.3.1 Verification standards and trading platforms $\quad \underline{19}$

5.3.2 Businesses with net zero targets $\underline{19}$

6 Conclusion $\underline{20}$

Acknowledgements $\quad \underline{21}$ 


\section{Executive summary}

Nature-based solutions to climate change use plants to draw carbon dioxide from the atmosphere, either by preserving and managing existing ecosystems or by creating new carbon sinks to sequester additional carbon from the atmosphere. Although the most common types of nature-based solutions to climate change involve forests, they can also involve other ecosystems such as wetlands, oceans, or even agricultural land. These solutions offer unique benefits, including the ability to preserve important ecosystems and positively impact communities in the developing world. At the same time, nature-based solutions must tackle particular challenges, including avoiding damage to these same communities and ecosystems, and ensuring that projects do not re-emit captured carbon into the atmosphere. The importance of nature in mitigating climate change is well-recognised, so it is important that these solutions are deployed at the necessary scale to meet global climate goals whilst minimising risks and maximising opportunities.

Carbon offsetting is a common but highly-debated strategy which involves organisations funding external emissions reductions or removals to meet climate goals. This is generally done by purchasing a 'carbon credit' that represents a certain amount of greenhouse gas emissions avoided or sequestered from the atmosphere. Offsetting is also a way of financing nature-based solutions to climate change. After making all feasible reductions in their own emissions, businesses can help to channel finance into nature-based solutions by offsetting their residual emissions, or by purchasing offsets to compensate for additional or historical emissions. However, offsetting using nature-based solutions may not always lead to reliable emissions reductions due to a number of distinct challenges. Emissions reductions must be additional to what would have occurred in the absence of an offsetting project, they must not lead to additional emissions outside of the project's scope, and they must be permanent, a particular challenge for nature-based solutions to climate change. Further, offsetting must be just and equitable, balancing the contribution to reducing climate change with the interests of local communities and with broader sustainable development goals.

These challenges may be addressed by different actors through a number of different actions. Policy frameworks can be designed to encourage organisations to offset only when appropriate, and to purchase high-integrity carbon credits. Governments can also develop clear standards that minimise risks associated with carbon offsets, and may help steer international negotiations towards effective management of the voluntary carbon market. Technology can also play a key role in improving offsetting using nature-based solutions through creating new types of nature-based solutions, making monitoring processes more accurate and efficient, and creating more effective accreditation and trading platforms. Private voluntary standards can continue to enhance their methodologies and registration processes in order to use innovative nature-based solutions to climate change while mitigating risks. Finally, organisations looking to purchase offsets can gain an understanding of the opportunities and challenges discussed in this paper so that they can purchase high-integrity offsets as part of a carefully considered climate strategy.

\section{Introduction}

Although anthropogenic climate change is already bringing varied and far-reaching impacts, it has become increasingly clear that the world is not doing enough to avoid more destructive and even catastrophic impacts. A recent assessment by the 
Intergovernmental Panel on Climate Change (IPCC) confirmed that every region of the world will be affected by climate change, and that drastic action will be required to limit global warming to 1.5 or 2 degrees above pre-industrial levels. ${ }^{1}$ Just as every business and government must prepare for the risks posed by climate change, they also share a responsibility to adjust their activities in line with climate goals. It is widely recognised that highly industrialised countries such as the UK should be leading the way with bold climate action. This is not only because of greater availability of resources, but also due to the outsized contribution many of these countries have made to historical carbon emissions. To limit human-caused climate change, the sum of a business or country's activities should not add carbon dioxide or other greenhouse gases to the atmosphere. Under the Climate Change Act, the UK is committed to reaching 'net zero' greenhouse gas emissions by 2050. ${ }^{2}$ The UK's recently published Net Zero Strategy sets out a range of government policies and proposals to meet this ambition, including a section on greenhouse gas removals and the need to balance residual emissions from the hardest to decarbonise sectors including aviation, agriculture, and heavy industry. ${ }^{3}$ This commitment is being matched by a growing number of businesses aiming to minimise their impact on the climate. Ambitious targets are an important step, but these ambitions must be urgently translated into meaningful climate action to have any chance of staying within 1.5 degrees of average warming compared to pre-industrial levels.

This document builds on interdisciplinary discussions within the Cambridge Zero Policy Forum to evaluate how and when organisations might choose to meet climate targets by funding nature-based solutions to climate change through carbon offsetting. Rather than providing specific recommendations, the discussion paper outlines key issues and challenges facing nature-based solutions and carbon offsetting, and describes a range of measures which may help to resolve these issues. In doing so, the paper aims to make public and private sector decision makers aware of the key challenges and opportunities associated with offsetting using nature-based solutions and provides a starting point from which they can consider whether and how they might implement these solutions.

The first and most important step for any business or government looking to minimise their contribution to climate change is to reduce the amount of greenhouse gases directly emitted from human activity. Certain sectors have made good progress towards this aim but others have a long way to go. The UK's electricity grid, for example, has become increasingly powered by renewable sources in recent years. ${ }^{4}$ On the other hand, many aspects of transport including aviation and freight are more difficult to decarbonise and need to overcome technological barriers before they can reach zero emissions. Although most governments and businesses could go far further in making feasible emissions reductions, these difficult to decarbonise sectors present a significant obstacle to full decarbonisation. To account for these 'hard-to-abate' emissions, organisations have two choices. They might fund or support emissions reductions in areas or sectors outside of their usual scope of activities. Alternatively, they may choose to sequester greenhouse gases from the atmosphere through technical, natural or geological greenhouse gas removal methods. 'Carbon offsetting' occurs when an organisation pays for one of these two services and subtracts the funded emissions reductions or greenhouse gas removal from their own total emissions. Offsetting has seen both increasing use and interest, as well as criticism as a means for meeting climate targets.

One way of both mitigating carbon emissions and also sequestering additional carbon from the atmosphere is using nature-based solutions to climate change. These methods protect, manage, or restore ecosystems, or create new natural carbon sinks, to reduce net emissions. These nature-based

$2 \quad$ Climate Change Act 2008, Section 1. The UK has also committed to reducing emissions by $78 \%$ compared to 1990 levels by 2035.

3 Department for Business, Energy and Industrial Strategy. October 2021. Net Zero Strategy: Build Back Greener. https://www. gov.uk/government/publications/net-zero-strategy.

$4 \quad$ Department for Business, Energy and Industrial Strategy, 2021. Energy Trends UK January to March 2021. Energy Trends June 2021 (publishing.service.gov.uk). 
solutions face risks and challenges and the suitability of some of these solutions for meeting climate goals is often challenged. The emissions reductions or carbon removals resulting from nature-based solutions may be sold as 'carbon credits' and purchased by businesses, governments, or individuals looking to offset their emissions. Section 3 of this paper summarises different nature-based solutions to climate change including how they can impact the climate, communities and ecosystems. Section 4 explains offsetting and gives an overview of the key risks and challenges that make this a controversial strategy. Section 5 presents a range of potential solutions that could improve the integrity of offsetting using nature-based solutions. Finally, Section 6 summarises the topics discussed in the paper.

\section{Nature-based solutions to climate change}

\subsection{Summary of nature-based solutions}

To gather energy through photosynthesis, plants capture carbon dioxide from the atmosphere. This biological process underpins nature-based solutions to climate change, which aim to increase the volume of carbon sequestered by nature. Nature-based solutions can involve either mitigating climate change by protecting existing natural carbon sinks, or growing new plants to capture additional carbon from the atmosphere. The most common types of nature-based solutions to climate change increase the carbon sequestered by forests, but these solutions may also involve wetlands, agricultural land or other natural areas. A range of different nature-based solutions and their advantages and drawbacks are discussed below. It is worth noting that nature may also play a key role in helping humans adapt to and manage climate risks. ${ }^{5}$ Though nature's potential to help adaptation efforts is important, this paper will primarily focus on nature-based solutions which aim to mitigate climate change.

Nature-based solutions might be financed directly by governments, including through international aid, or by the private sector through philanthropy or because of other commercial drivers such as the economic benefits derived from well-managed forests. By contrast, offsetting involves selling emissions reductions or removals from nature-based solutions as 'carbon credits' so that businesses, governments, or individuals can count these reductions towards their own climate goals.

Although almost every country could utilise nature-based solutions to climate change in some way, these solutions tend to be concentrated in places with large areas of forest cover. Many of these areas are in the tropics, particularly SouthEast Asia, Africa, and Latin America. ${ }^{6}$ Nature-based solutions are often most deployable and scalable in developing countries, many of which have high rates of deforestation (with accompanying greenhouse gas emissions) and may lack resources to protect their forests and other carbon sinks. Consequently, there have been many initiatives that aim to allow governments and businesses in highly developed countries to finance and support projects abroad. The use of nature to address climate change is therefore strongly tied to sustainable development. Indeed, any discussion of offsetting should consider the impacts of this strategy on the developing world generally, and specific peoples and communities affected by offsetting projects. The UNFCCC has acknowledged the importance of these solutions for tackling climate change, preserving biodiversity, and fostering development through global initiatives such as 'REDD+'. REDD+, however, has faced significant challenges including allegations of abuses to the rights of indigenous communities. $^{8}$

Most projections now confirm that in addition to drastic emission reductions, removing carbon from the atmosphere is necessary to limiting 
global warming to 1.5 or 2 degrees on average above pre-industrial levels. Carbon drawdown and removal is required under all IPCC 1.5-degree pathways, though the choice of removal method varies between pathways. ${ }^{9}$ Given that many technical and geological methods for removing carbon are not yet scalable or require further technological development, a significant portion of these removals are likely to come from nature-based solutions. In addition to greenhouse gas removal, nature-based solutions that limit potential damage to nature can also play a key role in avoiding future emissions. Analysis by McKinsey and the World Economic Forum suggests that nature-based solutions may provide up to one third of the net emissions reductions required by 2030 to limit warming to 1.5 degrees. ${ }^{10}$ In the UK, the Climate Change Committee has recognised the utility of nature-based solutions for meeting the nation's climate targets in its Sixth Carbon Budget. ${ }^{11}$ They are also included as playing a key role within the Government's recently announced Net Zero Strategy.

In summary, nature-based solutions are one of a range of solutions to the multidimensional challenge of climate change. Several questions remain, including which types of solutions should be used and how these solutions should be deployed and funded. This discussion paper explores the advantages and disadvantages of carbon offsetting as a funding method for nature-based solutions and outlines a range of measures that could improve this method of funding.

\subsection{Types of nature-based solutions}

There are many different types of nature-based solutions to climate change. This section outlines some of these solutions, divided by the broad type of nature which they utilise. Some of the methods listed below have already seen large-scale deployment and have well-understood advantages and risks. Others are emerging solutions supported by research but yet to be deployed at scale. Given the scale of the climate crisis, it is worth considering and understanding the full range of nature-based solutions to climate change.

\subsubsection{Forests}

Avoided deforestation involves protecting areas of forest that would have otherwise been cleared. ${ }^{12}$ In addition to reducing emissions, this method can combat other harms of deforestation including biodiversity loss. The emissions reductions claimed by an avoided deforestation project are estimated by comparing the actual emissions (or carbon sequestration) from the forested area with a counterfactual based on the volume of emissions that would have occurred were it not for the project. The difficulty in creating an accurate and credible counterfactual, in addition to other issues explored in section 4 of this paper, has made many groups and individuals call avoided deforestation into question as a means for meeting climate goals. Nonetheless, it remains a popular and common nature-based solution to climate change.

Reforestation is the practice of re-establishing a forest where there was one in the past. ${ }^{13}$ While eventually leading to net negative emissions, in the short-term reforestation can cause emissions of greenhouse gases to the atmosphere. Whilst trees absorb carbon via photosynthesis, they also emit volatile organic compounds (VOCs) which can react with the atmosphere forming ozone and lengthening the lifetime of atmospheric methane, both of which are greenhouse gases. There are also challenges of land-use competition which could lead to emissions elsewhere.

Afforestation involves the repurposing of land by growing forests where there were none in recent history. ${ }^{14}$ While afforestation can capture large amounts of atmospheric carbon over time, it requires significant land resources for which there may be competing uses and can pose risks

\footnotetext{
9 Intergovernmental Panel on Climate Change. 2015. Mitigation Pathways Compatible with $1.5^{\circ} \mathrm{C}$ in the Context of Sustainable Development in Special Report on Global Warming of $1.5^{\circ} \mathrm{C}$.

10 World Economic Forum. 2021. Consultation: Nature and Net Zero.

11 Climate Change Committee. 2020. The Sixth Carbon Budget: The UK's Path to Net Zero.

12 Palmer, C, and Engel, S. 2009. 'Avoided deforestation: prospects for mitigating climate change' in Routledge explorations in environmental economics.

13 Bastin, J. et al. 2019. 'The Global Tree Restoration Potential' in Science.

14 Foster, E.; Healey, J.; Dymond, C. and Styles, D. 2021. 'Commercial afforestation can deliver effective climate change mitigation under multiple decarbonisation pathways' in Nature Communications.
} 
to biodiversity and ecosystem services if poorly executed. Afforestation, reforestation and forest management (see below) are already widely practiced around the world and are well understood.

Managing forests to address climate change involves the optimisation of existing forests for the purpose of greenhouse gas removal and storage in biomass, and avoids the risks of land-use competition associated with afforestation and reforestation. ${ }^{15}$ Research-led forest management can protect biodiversity and ecosystem services while increasing greenhouse gas removal (GGR) potential.

\subsubsection{Wetlands}

Wetland and peatland preservation can help to ensure these important habitats continue to draw $\mathrm{CO}_{2}$ from the air. ${ }^{16}$ Peat, permafrost and other wetland habitats are long-term carbon stores but face threats from agriculture and other human impacts. Coastal kelp, seagrass and mangrove habitats are significant 'blue carbon' resources but are globally threatened and could be restored. There is a significant knowledge base and high level of readiness surrounding protection and restoration methods

Wetland and peatland restoration projects are not as widely deployed as preservation projects, but could serve to remove additional carbon from the atmosphere by restoring these large carbon sinks. ${ }^{17}$

\subsubsection{Oceans}

Ocean fertilisation is the practice of adding nutrients (primarily iron) to the ocean to increase its capacity to absorb $\mathrm{CO}_{2}$ by encouraging the growth of phytoplankton, which are single-celled, photosynthetic microorganisms. ${ }^{18}$ Though the principles of ocean fertilisation approaches are well understood, further research is required to understand the actual carbon cycle, the potential risks, and associated costs before any consideration of this approach as a potential GGR solution at scale.

Farming macroalgae (kelp) allows photosynthetic capture of $\mathrm{CO}_{2}$ in marine habitats, potentially overcoming terrestrial land shortages. ${ }^{19}$ Coastal areas may have the nutrients required for this growth but farming in the open ocean is likely to require additional nutrient inputs, especially if farmed intensively. Research into kelp farming as a GGR solution, particularly in the deep ocean, is still in its infancy and pilots are required to validate carbon removals efficacy as well as potential ecological impacts.

\subsubsection{Soil and agriculture}

Agroforestry is a method whereby trees are reintroduced into an arable landscape to improve soil organic carbon, reduce erosion, improve biodiversity and, normally (but not always) to provide separate income from that derived from arable cultivation. ${ }^{20}$ Many afforestation and reforestation projects are actually carried out on farmland, so may amount to agroforestry. There is extensive literature on the benefits it brings to biodiversity and ecosystem services but estimates of GGR efficiency and cost are not yet available.

Soil carbon sequestration is the process of removing $\mathrm{CO}_{2}$ from the atmosphere by changing land management practices in such a way as to increase the carbon content of soil. ${ }^{21}$ This can involve management of vegetation, animals, water, nutrients, fire and tillage. After as little as a few decades soil can become saturated and require ongoing maintenance to avoid $\mathrm{CO}_{2}$ being re-emitted. There is also limited evidence of efficacy in certain contexts and a risk of increased emissions

15 Kohl, M.; Ehrhart, H.; Knauf, M. and Neupane, P. 2019. 'A viable indicator approach for assessing sustainable forest management in terms of carbon emissions and removals' in Ecological Indicators.

16 Taillardat, P.; Thompson, B.; Garneau, M.; Trottier, K. and Friess, D. 2020. 'Climate change mitigation potential of wetlands and the cost-effectiveness of their restoration' in Interface Focus.

$17 \quad$ Ibid.

18 Lampitt, R. et al. 2008. 'Ocean fertilization: a potential means of geoengineering?' in Philosophical Transactions of the Royal Society A.

19 Chung, I.K., Beardall, J., Mehta, S. et al. 2011. 'Using marine macroalgae for carbon sequestration: a critical appraisal' in the Journal of Applied Phycology.

20 Daniel, A. and Lovett, T. 2019. How Regenerative Agroforestry Could Solve the Climate Crisis. https://www.weforum.org/agenda/2019/12/what-is-agroforestry-climate-change/.

$21 \quad$ Paustian, K. et al. 2019. 'Soil C Sequestration as a Biological Negative Emission Strategy' in Frontiers in Climate. 
of Nitrous Oxide $\left(\mathrm{N}_{2} \mathrm{O}\right)$. This GGR solution is ready for implementation and many of the practices underpinning soil carbon sequestration are already being used.

Biochar-charcoal produced from biomasscan be added to soils to enable carbon to remain stored for hundreds or thousands of years. ${ }^{22}$ There are risks to soil health due to the accumulation of heavy metals and organic contaminants. Research has indicated that biochar addition to soil may be an irreversible process, and the long-term effects are not well understood.

Enhanced weathering can accelerate natural processes that absorb $\mathrm{CO}_{2}$ (for example, by adding very fine mineral silicate rocks to soils). ${ }^{23}$ Immaturity of the technique means GGR potential is not yet fully understood, nor are the potential impacts on soil and water quality. The required minerals would need to be mined, transported and processed at a large scale, which would likely cause greenhouse gas emissions and other negative environmental impacts. Reversibility has not been demonstrated and further research is required on long-term effects. This GGR solution needs to be piloted in the field as current experience is primarily lab-based.

\subsection{Co-benefits and externalities}

Whilst often deployed primarily to reduce or remove carbon emissions, nature-based solutions to climate change can have profound impacts on people and natural areas. These impacts present both risks and opportunities. Nature-based solutions to climate change can offer co-benefits including preserving the biodiversity of natural areas and improving local economies, but they also have the potential to create negative externalities, harming biodiversity or communities.
Biodiversity loss is a major threat to humans and the environment distinct from, but linked to, climate change. In addition to any inherent value in having a diverse range of species and habitats, biodiversity provides enormous benefits in the form of 'natural capital'24 or 'ecosystem services' ${ }^{25}$ A recent report commissioned by HM Treasury confirms these values and argues that broad systemic changes are required to reconcile this issue with economic growth. ${ }^{26}$ Nature-based solutions can improve biodiversity by preserving or expanding important habitats. For example, a project that protects part of the Amazon rainforest from deforestation may both reduce potential emissions from land being cleared in the area whilst also preserving the abundance of unique species in the area.

Perhaps less obviously, nature-based solutions may actually pose a threat to biodiversity. The carbon stock of plant life is not necessarily representative of its importance to biodiversity goals. Planting a large monoculture of trees could increase the volume of emissions sequestered by a particular area while damaging its biodiversity. ${ }^{27}$ On the other hand, ensuring that forest carbon projects retain biodiversity may even be beneficial to climate goals, as research suggests that natural regeneration sequesters more carbon than dense monocultures. ${ }^{28}$ Balancing these two aims is vital to the integrity of nature-based solutions and presents a unique opportunity to simultaneously address two of the most serious environmental problems that the world is facing.

Nature-based solutions can also be important to local communities. If properly organised and financed, they can provide employment and economic growth in areas that are often very deprived. ${ }^{29}$ However, they may also create governance structures that negatively impact local

22 Woolf, D., Amonette, K., Street-Perrott, F., Lehmann, J. and Joseph, S. 2010. 'Sustainable biochar to mitigate global climate change' in Nature Communications.

23 Beerling, D. et al. 2020. 'Potential for large-scale CO2 removal via enhanced rock weathering with croplands' in Nature.

24 Natural Capital Committee. 2019. Natural Capital Terminology. https://assets.publishing.service.gov.uk/government/uploads/ system/uploads/attachment_data/file/909202/ncc-terminology.pdf.

$25 \quad$ United States Environmental Protection Agency. 2010. Summary: Ecosystem Services and Human Welfare. https://cfpub.epa. gov/si/si_public_record_report.cfm?dirEntryld=223655\&Lab=NERL.

26 Dasgupta, P. 2021. The Economics of Biodiversity: The Dasgupta Review. (London: HM Treasury).

$27 \quad$ Altieri, M. 'Green deserts: Monocultures and their impacts on biodiversity' in Red Sugar, Green Deserts: Latin American Report on Monocultures.

28 Kanowski, J. and Catterall, C. 2010. 'Carbon stocks in above-ground biomass of monoculture plantations, mixed species plantations and environmental restoration plantings in north-east Australia' in Ecological Management and Restoration. 
communities. ${ }^{30}$ Certain projects under the UN'S REDD+ initiative have been criticised for disregarding local land rights, often putting indigenous peoples' rights at risk. ${ }^{31}$ Not only can these risks be avoided, but projects can aim to let groups living in the area capture the benefits of naturebased projects. This might involve integrating all aspects of the local community into the project. ${ }^{32}$ Indeed, some studies suggest that land stewarded by indigenous groups may actually be most effective at preserving biodiversity and sequestering carbon. ${ }^{33}$

Co-benefits and negative externalities may be approached in several different ways. At a minimum, nature-based climate projects should do no harm to local communities or ecosystems. This is the minimum standard set by some carbon credit verification standards including the Verified Carbon Standard. ${ }^{34}$ Ideally, nature-based solutions should go beyond this threshold and aim to reap any possible co-benefits. Separate verification standards exist to approve carbon credits that actively benefit communities or biodiversity. ${ }^{35}$ Certain properties of offsets such as their impact on biodiversity could be quantified and priced. Bundling different qualities together tends to be economically inefficient, so it may be better to sell the biodiversity value and the emissions reductions from the same project separately. Other relevant impacts such as water quality ${ }^{36}$ and amenity value are more difficult to quantify but could be measured and attached to tokens or credits as labels. Similarly, it may be difficult to put a value on the broader benefits that naturebased solutions can bring to communities and economies. In any case, measuring and verifying these co-benefits can help to improve the effectiveness and integrity of nature-based solutions.

\section{Carbon offsetting}

\subsection{Summary of carbon offsetting}

Carbon offsetting is a process that involves a reduction in emissions, or removal from the atmosphere, of carbon dioxide or other greenhouse gases to compensate for emissions made elsewhere. It is both a strategy to account for residual emissions and an exchange mechanism intended to incentivise cost-effective emissions reductions or greenhouse gas removal. Offsetting generally involves companies, governments and other organisations paying other entities to reduce carbon emissions or sequester carbon and then counting those emissions reductions towards the buyer's climate targets. For example, a company that emitted 100 tonnes of $\mathrm{CO}_{2}$ in 2020 may reduce these emissions to 40 tonnes of $\mathrm{CO}_{2}$ in 2021 by switching to less carbon-intensive energy sources. To account for the residual emissions, it may purchase 'carbon credits' that represent 40 tonnes of $\mathrm{CO}_{2}$ that has been sequestered in an area that was reforested. This company may then claim to have reached 'net zero' through first directly reducing its own emissions and then funding sequestration elsewhere through offsetting. Although offsetting discussions tend to centre on large corporations using this strategy, certain initiatives have allowed individuals to offset emissions caused by their own personal actions. For example, some services allow individuals to offset their aviation emissions. ${ }^{37}$ Ultimately, offsetting aims to provide financial incentives for emissions reducing or sequestration projects and gives businesses a chance to take climate action outside the usual scope of their activities.

Although the amount of offsetting is modest at present when compared to total global emissions, it has become central to the discussion of how

\footnotetext{
30 Herr, D., Blum, J., Himes-Cornell, A. and Sutton-Grier, A. 2019. 'An analysis of the potential positive and negative livelihood impacts of coastal carbon offset projects' in The Journal of Environmental Management.

31 Naughton-Treves, L. and Wendland, K. 2014. 'Land Tenure and Tropical Forest Carbon Management' in World Development.

32 Shankar Pandey, S., Cockfield, G. and Narayan Maraseni, T. 2016. 'Assessing the roles of community forestry in climate

change mitigation and adaptation: A case study from Nepal' in Forest Ecology and Management.

33 Veit, P. 2021. 4 Ways Indigenous and Community Lands Can Reduce Emissions. World Resources Institute Website. https://www. wri.org/insights/4-ways-indigenous-and-community-lands-can-reduce-emissions.

34 Verra. 2019. VCS Standard. Section 3.16.1. https://verra.org/wp-content/uploads/2019/09/VCS_Standard_v4.0.pdf.

35 Verra. 2021. 'Climate, Communities and Biodiversity Standards' web page. https://verra.org/project/ccb-program/.

$36 \quad Y u$, Z. et al. 2018. 'Natural forests exhibit higher carbon sequestration and lower water consumption than planted forests in China' in Global Change Biology.

37 See for example: Hooker, L. 2019. Should I Offset my Summer Holiday Flights? BBC News. Should I offset my summer holiday flights? - BBC News.
} 
organisations should tackle climate change. Any activity that reduces greenhouse gas emissions or removes greenhouse gases from the atmosphere could theoretically be used to offset emissions. Money generated through selling carbon credits can finance a wide range of projects that aim to reduce emissions or sequester carbon in the future. Offsetting by funding nature-based solutions, the focus of this paper, has become popular. This popularity can be explained by the potential for co-benefits listed above, the existence of international frameworks that support these solutions and, perhaps most importantly, the fact that nature-based solutions tend to produce relatively cheap carbon offsets. Most nature-based offsetting involves forestry projects but other methods are being pioneered.

Understanding the basic process through which carbon offsets are generally created and sold is important to analysing this strategy's strengths and weaknesses. Nature-based projects themselves are generally carried out by an organisation or group based near the project's location, but often receive funding and support from abroad. If they wish to sell their projects' emissions reductions or removals as a carbon credit, they must follow specific methodologies approved by a bona fide carbon verification standard. There is no universal carbon standard, but most projects are verified by a select few well-established standards such as the Gold Standard ${ }^{38}$ and the Verified Carbon Standard. ${ }^{39}$ After reviewing a project's data and assessing its claimed emissions reductions, verifiers will issue the project with carbon credits that represent the volume of emissions reductions achieved by that project. It is important to note that even well-established standards often fail to deliver claimed emissions reductions or social benefits. ${ }^{40}$ These carbon credits can then be held as inventory or sold, either directly or through an intermediary, to organisations or individuals looking to offset their emissions, who may then retire the carbon credit.
Another aspect of offsetting to consider is how this concept interacts with emissions trading systems. Regulated carbon markets require polluters to pay for emissions allowances, of which there are a limited supply, if they wish to emit carbon dioxide or other greenhouse gases. Due to certain key risks listed below, and to ensure that companies directly change their own behaviour, some major carbon markets do not accept the use of voluntary offsets as a means to increase the total amount of carbon a company may emit. The EU's Emissions Trading System, at present the largest in the world, is disallowing the use of offsets and has encouraged other markets to do the same. ${ }^{41}$ On the other hand, the International Civil Aviation Organization's (ICAO) new trading system will rely heavily on carbon offsetting because low or zero-carbon aviation is some years from being technologically viable. ${ }^{42}$

Historically there has been low trust in voluntary carbon markets. In addition to fundamental challenges in ensuring accurate emissions reductions, the proliferation of standards and protocols, and the complex web of organisations involved in selling carbon credits, has ultimately led some to view voluntary carbon markets as convoluted and opaque. Even so, given the difficulties that major emitters face in rapidly reducing their own direct emissions to zero, these markets could play an increasingly important role in meeting climate ambitions and may therefore need to be scaled up rapidly. Fostering and maintaining transparency and credibility will be a key hurdle to be overcome as the voluntary carbon market grows. These issues are widely acknowledged, and action is starting to be taken. For example, the Institute for International Finance (IIF) established the Taskforce on Scaling Voluntary Carbon Markets (TSVCM) in late 2020. In September 2021 the TSVCM announced the creation of a new governance body to help regulate voluntary carbon markets and finalise the creation of the Core Carbon Principles, which

\footnotetext{
38 Gold Standard. 2021. 'Gold Standard for the Global Goals' web page. https://www.goldstandard.org/our-story/gold-standardglobal-goals.

$39 \quad$ See footnote 34

40 Compensate. 2020. Reforming the Voluntary Carbon Market. https://www.compensate.com/reforming-the-voluntary-carbonmarket\#download-white-paper.

41 Dalunde, J. and other MEPs. 2019. Open Letter on the Tropical Forest Standard. https://www.politico.eu/wp-content/uploads/2019/04/Open-letter-on-the-Tropical-Forest-Standard-EU-Parliament.pdf.

42 International Civil Aviation Organization. 2019. CORSIA Emissions Unit Eligibility Criteria. https://www.icao.int/environmental-protection/CORSIA/Documents/ICAO_Document_09.pdf.
} 
are envisioned to act as the global benchmark for carbon credit integrity. ${ }^{43}$

For any organisation, carbon offsetting should be a supplement to, rather than a replacement for, reducing the organisation's own direct emissions as far as possible. Ideally, a company would only purchase a carbon credit to offset emissions that are impossible to eliminate due to technical barriers, or for emissions reductions that are over and above what they need to be firmly aligned with global climate goals. However, the reality is that many organisations do use carbon offsetting before making all feasible direct emissions reductions, often because meeting climate goals becomes cheaper or easier by offsetting. Section 4.3 goes into greater detail on how offsetting might best fit into corporate climate ambitions. In any case, it is important that the significant amount of money flowing into offsetting goes towards projects with environmental integrity. The following section outlines key risks that must be managed to ensure effective offsetting using nature-based solutions.

\subsection{Key risks associated with carbon offsetting}

Carbon offsetting raises a number of risks and challenges, some of which are common to all forms of offsetting, and others which are unique to nature-based solutions. Section 3.3 explained how nature-based solutions need to mitigate risks to ecosystems and communities. This section explores more fundamental risks of carbon offsetting using nature-based solutions that can jeopardise this method's primary goal of reducing emissions.

\subsubsection{Additionality}

For offsetting to be accepted as credibly contributing to the protection of climate stability, emissions reductions from offsetting projects must be additional to any reductions that would have occurred in the absence of the project. Thus, calculating the volume of emissions reduced by an offsetting project requires two separate projections-one which estimates the change in carbon over a project's lifespan, and another which estimates that same trajectory if the project were not to occur over the same time period. ${ }^{44}$ While a project's estimated emissions reductions are calculated at the outset, credits are often issued retrospectively. If these estimations are incorrect, the projected emissions reductions from a project may be lower than the actual reductions, which means buyers will not have an accurate picture of the actual impact of purchasing carbon offsets. Although carbon sequestration may in fact be higher than initially expected, this additional natural sequestration should not then be counted towards a country's emissions reductions. ${ }^{45}$

Ensuring additionality from nature-based solutions to climate change requires an accurate assessment of a project's past and projected impact on emissions, a credible counterfactual-a baseline that gives the volume of emissions that would have occurred in the absence of that project, and sound monitoring of a project over time. Depending on the project, a counterfactual may be statistically generated and compared to what happened in the project site by using publicly available geospatial data. Estimating the extent of additionality typically requires inputs from multiple different parties. Verification standards have detailed accreditation models that include specific technical methodologies that aim to ensure additionality for different project types. ${ }^{46}$ Projects are also usually independently reviewed by a consultant and third-party auditor. However, much of the specific data and information used in assessing a project is often provided by the project developer. This means that uncertainties surrounding the accuracy of a baseline may be difficult to avoid, and the actual impact of offsetting may not be clear. Ultimately, inaccurate baselines risk credits that overstate emissions reductions, an effect which has been observed in REDD+ projects. ${ }^{47}$

43 Institute for International Finance. 2021. TCSVCM Phase 2 Report Summary. https://www.iif.com/Portals/1/Files/TSVCM_

Phase_2_Report_Summary.pdf.

$44 \quad$ Valatin, G. 2011. Forests and Carbon: A Review of Additionality. Forestry Commission: Edinburgh.

45 Pearce, F. 2021. 'Will Russia's Forests be an Asset or an Obstacle in Climate Fight?' in Yale Environment 360. https://e360.yale. edu/features/will-russias-forests-be-an-asset-or-obstacle-in-the-climate-fight.

$46 \quad$ GHG Management Institute and the Stockholm Environment Institute. 'How Carbon Offset Programs Address Additionality'. Carbon Offset Guide. https://www.offsetguide.org/high-quality-offsets/additionality/high-quality-offsets-additionality-how-carbon-offset-programs-address-additionality/.

$47 \quad$ West, T., Börner, J., Sills, E. and Kontoleon, A. 2020. 'Overstated carbon emission reductions from voluntary REDD+ projects in the Brazilian Amazon' in Proceedings of the National Academy of Sciences of the United States of America. 


\subsubsection{Carbon leakage}

In the context of offsetting, carbon leakage occurs when, as a result of the activities generating emissions reductions in the project area, emissions increase elsewhere. ${ }^{48}$ This happens when emissive economic activity moves location because of constraints imposed by an offsetting project. Thus, the net benefit of any offsetting project should be adjusted to account for emissions that have 'leaked' elsewhere as a result of the project. For example, a project may prevent deforestation and effectively reduce emissions in that project's area. However, if that land was to have been cleared to produce certain goods, such as timber or livestock, land may be cleared elsewhere in order to meet the demand for those goods.

In nature-based carbon projects, leakage is often first accounted for ex ante through a default market leakage rate. Subsequent estimation of land-use change in surrounding areas can provide a more robust estimate of the extent to which emissions have leaked locally. However, given the global scope of supply chains, emissions reductions in one place may also cause an increase in non-local emissions. The propensity for overall leakage may be roughly estimated by calculating the forgone production of certain goods and looking at where that production may be met. Policy mechanisms such as carbon border adjustments may help mitigate the negative effects of international leakage, ${ }^{49}$ though their broader impacts on trade, particularly with the developing world, should be considered. ${ }^{50}$

Since carbon leakage affects projects that protect natural areas from the impacts of economic activities, it may be less of a salient risk to naturebased solutions that aim to remove additional carbon from the atmosphere.

\subsubsection{Permanence}

One key challenge affecting nature-based solutions is that natural carbon sinks may not be permanent. When destroyed or burned, plants release their captured carbon into the atmosphere. This is in contrast to reducing industrial emissions, which does not face these issues, and to geological carbon storage methods, which have a much lower likelihood of releasing carbon back into the atmosphere. ${ }^{51}$ In practice, nature-based solutions may release carbon due to fires or other catastrophic events, or simply because natural areas are cleared by regular human activity. ${ }^{52}$ It is therefore imperative that nature-based solutions not only ensure the immediate protection of existing biomass or creation of new plants, but that these areas are effectively managed and preserved over time.

Additionality calculations are typically timebound and demonstrate a reduction in atmospheric carbon over that period (as compared to the counterfactual scenario). However, at the end of the project period, enhanced carbon stocks may revert to the atmosphere at an estimable rate. One plausible forecast is that in the absence of the carbon project, emissions revert to the business-as-usual rate. For example, deforestation recommences but not faster than average, given the environmental conditions. Alternatively, it is possible that carbon stocks are re-emitted instantaneously through a catastrophic failure, such as a fire that burns through the project site. This has already happened in the western USA. Recent fires in 2020 and 2021 have burned hundreds of thousands of acres that are part of offset projects in California and Oregon..$^{53}$ The likelihood of such fires may increase if projects are planted which involve dense monocultures of oil or resin-rich trees. ${ }^{54}$

\footnotetext{
48 Ye, H., Zhang, Q., Pan, X. and Farnoosh, A. 2020. 'Market-induced carbon leakage in China's certified emission reduction projects' in Mitigation and Adaptation Strategies for Global Change.

$49 \quad$ European Commission. 2021. Carbon Border Adjustment Mechanism web page. https://ec.europa.eu/taxation_customs/ green-taxation-0/carbon-border-adjustment-mechanism_en .

$50 \quad$ United Nations Conference on Trade and Development. 2021. EU Should Consider Trade Impacts of New Climate Change Mechanism. https://unctad.org/news/eu-should-consider-trade-impacts-new-climate-change-mechanism.

51 Alcalde, J. et al. 2018. 'Estimating the geological CO2 storage security to deliver on climate mitigation' in Nature Communications.

52 GHG Management Institute and the Stockholm Environment Institute. Permanence. Carbon Offset Guide. https://www.offsetguide.org/high-quality-offsets/permanence/.

53 Choi-Schagrin, W. (2021) "Wildfires are ravaging forests set aside to soak up greenhouse gases." New York Times. https:// www.nytimes.com/2021/08/23/us/wildfires-carbon-offsets.html.

$54 \quad$ Montiel, R. et al. 2021. 'Eucalypt plantations for forest restoration in a fire-prone mosaic of grasslands and forests in northern Argentina' in Restoration Ecology.
} 
Nature-based solutions are important as they can reduce emissions in the near future, while other sectors develop the technologies required to decarbonise. True permanence, storing carbon over extremely long timescales, may therefore not be as important as simply mitigating these risks over the next century. In addition to increasing the level of data and knowledge about nature-based offsetting projects, regularly monitoring project sites is important to ensure that carbon stores remain in place over years and decades. Further, projects that positively impact local economies over an extended period of time are more likely to ensure permanence by avoiding shifting back to activity that did not preserve relevant natural carbon sinks.

\subsubsection{Double counting}

'Double counting' refers to a number of situations in which emissions reductions from one project are counted towards multiple climate targets, goals, or limits. This is a key hurdle at the international level-a project's host country and the country from which an offset is being bought might both claim the emissions reductions towards their Nationally Determined Contributions under the Paris Agreement. ${ }^{55}$ In this situation, actual progress towards emissions targets would be lower than reported. Double counting may also occur when a carbon credit buyer counts reductions towards their voluntary climate goals that have already been claimed by the host country. A more egregious form of double counting labelled 'double registration' occurs when a project is registered under two separate standards. Double registration can be avoided by comparing registries. ${ }^{56}$

\subsubsection{Broader ethical concerns}

The foregoing issues stem from specific aspects of offsetting and nature-based solutions that risk projected emissions reductions being higher than actual reductions achieved. Putting these technical issues aside, offsetting is often criticised for being unethical in principle. Offsetting often involves organisations in the wealthiest parts of the world paying people in the developing world to reduce their emissions, often paying very low prices, instead of reducing their emissions directly. This has led some critics to compare offsetting to 'selling indulgences'. ${ }^{57}$ The economies that purchase the most carbon offsets tend to have had a large impact on historical greenhouse gas emissions. By contrast, nature-based projects are often based in areas that have had a minimal impact on global emissions. Many are uncomfortable with extremely wealthy businesses paying to avoid taking direct action to reduce these emissions, arguing that they have a particular responsibility to reduce their own emissions. These criticisms are amplified by the issues discussed above that mean businesses may not even be funding the right volume of real emissions reductions.

This criticism is particularly relevant to organisations that have not made a strong enough effort to make direct emissions reductions. For organisations that are using offsetting to account for emissions that are particularly difficult to reduce due to technical barriers, these concerns may not be as relevant. In any case, businesses are likely to continue to utilise carbon offsetting for the foreseeable future. As long as they continue to do so, it is important to understand the risks associated with offsetting and take action to improve its integrity.

\subsection{Offsetting and corporate climate strategies}

While emissions reduction should be the primary focus of corporate climate strategies, offsetting might play a role when a business cannot directly reduce all of its emissions or wants to go above and beyond net zero targets. The extent to which offsetting is suitable for an individual business is therefore highly dependent on sector. Companies in harder-to-abate sectors (including cement, steel, plastics, heavy duty transport, and aviation) may need to deploy offsets at a larger scale to make necessary emissions reductions. These sectoral 
differences in offsetting strategy are reflected in the Climate Change Committee's recommendations on reaching net zero in the UK. ${ }^{58}$ Certain standards exist to help determine where offsetting could fit in with climate strategies. ${ }^{59}$ Certifying a business against these standards may help to ensure a robust climate strategy and decrease financial and reputational risks to the companies.

One particular strategy a business may consider for carbon offsetting is 'insetting', where the business chooses to fund or develop emissions-reducing or removal activity within its own supply chain..$^{60}$ For example, a business in the food industry might help to deploy regenerative agriculture or agroforestry within the farms from which it purchases food. Insetting in this case offers the benefits of offsetting whilst also focusing on the business's own value chain. However, the extent to which a business can deploy this approach will vary depending on the specific nature of its value chain. The International Carbon Reduction $\&$ Offset Alliance (ICROA) offers some guidance on insetting best practice. ${ }^{61}$

Businesses that can effectively reduce their own emissions might purchase carbon credits separately from their net zero strategy as part of broader sustainability efforts. Carbon credits also present a means to finance emissions reductions additional to meeting net zero goals through direct action. Indeed, this is the role of offsets envisioned by the Science Based Targets Initiative. ${ }^{62}$ Some companies have set specific targets beyond net zero, including aiming to offset all historical emissions. ${ }^{63}$ A business's capacity to purchase carbon credits taking it beyond net zero (i.e. towards 'net negative' emissions) will vary; however, it is important to recognise this option as an addition to systemic change within a company's own activities, and an opportunity to fund external emissions-reducing projects.
5 Measures that can improve offsetting using nature-based solutions

\subsection{Policy measures}

Although carbon offsetting is often a solution used in the private sector, governments have a key role to play in ensuring that offsetting is used at appropriate times and with sufficient safeguards. They can do this through a wide range of policy measures, some of which are outlined below.

\subsubsection{Directly integrating offsetting into govern- ment strategy}

As mentioned earlier in this paper, regulated carbon markets involve a government putting a cap on emissions across a sector or geographical area and issuing a number of 'allowances' equivalent to that emissions cap. Businesses can then trade these allowances. Within these systems, governments may choose to allow businesses to offset particular sources of emissions to stay within their allowance. Here, regulators should carefully determine which emissions within their trading system are so sufficiently difficult to abate that offsetting is necessary. For most emissions trading systems, it may be better to remain fully separate from the voluntary carbon market. If a government or international governmental organisation does decide to rely heavily on offsetting, such as within the ICAO's Carbon Offsetting and Reduction Scheme for International Aviation (CORSIA), it may then review existing credits and standards in light of the key risks of offsetting. Governments and intergovernmental bodies may consider allowing standards and credits which effectively manage these risks and issue high-integrity offsets within their trading system.

\footnotetext{
58 Climate Change Committee. 2019. Net Zero: The UK's Contribution to Stopping Global Warming. https://www.theccc.org.uk/ wp-content/uploads/2019/05/Net-Zero-The-UKs-contribution-to-stopping-global-warming.pdf.

59 British Standards Institution. 2021. PAS 2060 Carbon Neutrality. https://www.bsigroup.com/en-GB/PAS-2060-Carbon-Neu-

trality/.

60 Insetting Platform. 2021. Insetting Explained. Insetting Platform Web Site. https://www.insettingplatform.com/insetting-explained/.

61 International Carbon Reduction \& Offsetting Alliance. 2016. Insetting: Developing Carbon Offset Projects Within a Company's Own Supply Chain and Supply Chain Communities. https://www.icroa.org/resources/Pictures/ICROA\%20Insetting\%20Report_v300.pdf.

62 Science Based Targets Initiative. 2021. FAQs. Science Based Targets Web Site. https://sciencebasedtargets.org/faqs.

63 Joppa, L., Luers, A., Willmott., E., Friedmann, S., Hamburg, S. and Broze, R. 2021. 'Microsoft's million-tonne CO2-removal purchase' in Nature. https://www.nature.com/articles/d41586-021-02606-3.
} 
Governments may also choose to create and support programmes that allow consumers to offset emissions from hard-to-abate sectors; for example, the UK government's consultation on offsetting in the transportation sector. ${ }^{64}$ Here, governments must again be careful not to promote or facilitate offsetting where direct reductions are possible and preferable. One benefit of this approach is that governments can play a more direct role in determining which offsets might count in such a scheme and creating safeguards that ensure the risks outlined in this paper are mitigated. Through these initiatives, governments could also take steps to educate individuals on carbon offsetting and the extent to which it can play a role in addressing climate change.

\subsubsection{Investment in technologies}

Section 3.2 outlined a wide range of nature-based solutions to climate change, but only some of those solutions are ready for widespread use. Rapid programmes of research and development to address remaining knowledge gaps, accelerate new methodologies and technologies, and to fund, construct and evaluate pilot projects could help make more methods viable for deployment. Deploying as many methods as possible may be needed to reach the scale of emissions reductions and removals required and, because many nature-based solutions are land or resource-intensive, to avoid using too much of one type of resource. In addition to directly funding and creating projects, the government may use policy levers such as tax credits to encourage the use of new solutions. ${ }^{65}$ Similarly, governments could consider piloting projects that aim to enhance offsetting through emerging digital technologies to accelerate this technological shift. Section 5.2 explores these technological solutions in greater detail.

\subsubsection{Other climate policies}

Many broader policies that aim to reduce carbon emissions can have positive impacts on carbon offsetting. Command-and-control measures such as technical standards or prohibitions on certain practices may force systemic change in industries and help to mitigate the risk that offsetting delays this change. Carbon pricing, including both taxation and emissions trading, should make carbon emissions more costly for businesses. ${ }^{66}$ The more expensive it is to continue emitting, the more likely companies are to actually reduce these practices rather than continue them. Stringent emissions reporting and disclosure standards are important climate policies that may also benefit carbon offsetting (e.g. the Taskforce on Climate-related Financial Disclosures). Ensuring that businesses have accounted for the full range of emissions within their value chain may lead to more considered corporate climate strategies. Reporting and disclosure standards also open up a business's climate accounts to further scrutiny and public pressure, helping to ensure it is not offsetting emissions where it could otherwise make direct reductions. Reporting in line with these standards may also help to highlight key opportunities for businesses to 'inset' emissions by deploying naturebased solutions within their value chains.

International climate policy is a final important aspect of a government's ability to encourage smart offsetting. Encouraging sustainable development through international aid and capacity building could incentivise certain developing countries and regions to deploy nature-based solutions to climate change within their own borders. With this in mind, it is important that international aid and development programmes remain ambitious. Finance by offsetting through nature-based solutions is just one potential part of the puzzle. Climate change, be it through mitigation, greenhouse gas removal, or adaptation, will continue to be an ever-expanding area for international development policy. The allocation of more funding for smart carbon offsetting initiatives should not be at the expense of other vital aid and development programmes, which also serve a key role in fostering resilience to the impacts of climate change. The funding for

\footnotetext{
64 Department for Transport. 2021. Carbon Offsetting in Transport: Government Response. https://www.gov.uk/government/consultations/carbon-offsetting-in-transport-a-call-for-evidence/outcome/carbon-offsetting-in-transport-government-response. 65 See for example the United States of America's tax credit for carbon capture and storage: https://www.whitecase.com/publications/insight/carbon-capture/us-tax-credit-encourages-investment.

66 World Bank. 2021. What is Carbon Pricing? Carbon Pricing Dashboard. https://carbonpricingdashboard.worldbank.org/ what-carbon-pricing.
} 
offsetting through nature-based solutions should be new and additional rather than reallocated. ${ }^{67}$

Furthermore, international negotiations relating to Article 6 of the Paris Agreement could help to create a successor to the Clean Development Mechanism that better safeguards against the various risks of carbon offsetting. ${ }^{68}$ Promoting and supporting other relevant international initiatives such as the Taskforce on Scaling Voluntary Carbon Markets $^{69}$ and the recently established Voluntary Carbon Market Integrity Initiative ${ }^{70}$ may also help to ensure that the world deploys carbon offsetting with integrity, and at a large enough scale to deliver the emissions reductions necessary for reaching international climate targets. These initiatives still, however, face criticism for their commitment to carbon offsetting as a key climate solution. ${ }^{71}$

\subsection{Technological measures}

Emerging technologies can play a key role in improving the integrity of carbon offsetting. Both the public and private sector may fund and deploy these technologies, drawing on the policy solutions listed above, and the business solutions outlined in section 5.3.

\subsubsection{Emerging nature-based solutions}

The most fundamental technological advancements that could improve carbon offsetting relate to the nature-based solutions themselves. Despite the wide range of potential nature-based solutions outlined in Section 5.3, only a few nature-based solutions are commonly deployed and sold as offsets. This is in large part due to certain methods being relatively untested in practice, or not yet deployed at scale. Emerging solutions such as biochar and enhanced weathering promise carbon removal without facing many of the risks that restoring ecosystems does. Ocean-based solutions such as ocean fertilisation and macroalgae farming are also relatively untested but, if effective, could be scaled up to an even greater extent than terrestrial approaches. ${ }^{72}$

Many of these new methods could partially alleviate concerns about additionality and permanence. As most of these methods aim to remove additional carbon from the atmosphere rather than protecting existing carbon sinks, it may be easier to generate an accurate counterfactual or baseline level of emissions. Methods that do not rely on areas of nature that are often degraded or cleared due to human activity or natural disasters have the potential to store carbon for longer time periods than forestry projects. Carbon credits generated from these projects may therefore offer more reliable estimates of total emissions reductions.

It is important to note that emerging naturebased solutions may face challenges when and if they are eventually deployed at a large scale. In any case, the voluntary carbon market needs to be improved immediately given how little time remains to reach many climate targets. It is therefore imperative that current nature-based solutions are optimised even if they may later be replaced or supplemented by newer techniques.

\subsubsection{Improved measurement, reporting and verification}

In order to calculate emissions reductions or removals, nature-based solutions must be monitored carefully-this process is referred to as measurement, reporting and verification (MRV). Improving the accuracy of MRV processes could give a better picture of a project's actual impact, in turn producing more accurate and reliable carbon credits. Improving the speed, cost, and efficiency of these processes is also

67 Norton, A. 2021. UK Aid Cuts Threaten Climate Leadership Role of COP26 President. IIED website. https://www.iied.org/uk-aidcuts-threaten-climate-leadership-role-cop26-president.

68 Article 6.4, Paris Agreement to the United Nations Framework Convention on Climate Change, Dec. $12,2015$.

69 Institute of International Finance. 2021. Taskforce on Scaling Voluntary Carbon Markets web page. https://www.iif.com/

tsvem.

$70 \quad$ Voluntary Carbon Markets Integrity Initiative. 2021. Aligning Voluntary Carbon Markets with the $1.5^{\circ} \mathrm{C}$ Paris Agreement Ambition. https://vcmintegrity.org/wp-content/uploads/2021/07/VCMI-Consultation-Report.pdf.

71 Reclaim Finance and Amazon Watch. 2021. Reclaim Finance and Amazon Watch's Response to the TSVCM Consultation. https:// reclaimfinance.org/site/wp-content/uploads/2021/06/Consultation-response-Letter-from-RF-and-AW-to-TSVCM-June-19th-2021. pdf.

72 Lebling, K. and Northrop, E. 2020. Leveraging the Ocean's Carbon Removal Potential. World Resources Institute. https://www. wri.org/insights/leveraging-oceans-carbon-removal-potential. 
important, as this could make it easier to establish new projects, allow for more frequent monitoring, or give projects the ability to monitor emissions across a larger land area. Technology can play a key role in improving MRV, as is evident from recent advances in forest monitoring.

Traditional forest carbon monitoring is labour-intensive, requiring the use of equipment including spray-paint, tape, compasses and GPS devices. Auditors must undergo extensive training and often travel long distances between plots of land. Data collected through these methods can then be sent to organisations that operate established standards such as the Woodland Carbon Code for verification. ${ }^{73}$ In contrast, the use of depth sensors in mobile phones to scan trees and monitor forests can be much quicker and easier. Terrestrial laser scanning, which involves sending laser pulses throughout a forest to create a three-dimensional view of woodland, can provide more accurate estimates of forest carbon stock. However, terrestrial laser scanning equipment is expensive and hard to deploy at scale. When mapping larger areas of forest, LIDAR scanning equipment can be attached to aircraft to get detailed three-dimensional plots. This is somewhat time-consuming, and even larger areas of land can be monitored using satellite imagery. ${ }^{74}$ This technique loses some detail compared to the other less remote methods, and cloud cover can make it difficult to obtain timely information on forest carbon stock.

Using these modern monitoring methods, the carbon stock of a forest could be measured on a yearly basis. Currently, forest carbon stock is usually evaluated once every five years. These modern methods may therefore help provide more accurate and timely data on nature-based climate solutions. The ideal frequency of measurement varies depending on how quickly circumstances are likely to change in a certain area, and whether one is measuring the area of forest coverage (which is easier to measure but can change quickly) or the biomass of a particular area of forest (which is more difficult to measure but less likely to change quickly). Measuring carbon in the soil of forests remains difficult using any of these techniques and hence is an important research need.

\subsubsection{Creating trust in carbon credits}

Another way that technology could improve offsetting using nature-based solutions is by ensuring more efficient and effective trading of carbon credits by making them more trustworthy. One potential approach would be shifting to blockchain-based trading. A blockchain is a globally visible ledger that is owned by no one yet can be trusted by everyone. Blockchains make transactions immutable by associating them with hashes and storing these hashes in a tamper-evident way. It is easy to go from a transaction to a hash but not the other way around; therefore, if the hash of a transaction is widely shared, the transaction cannot be silently modified. Blockchains also offer security as the network cannot be compromised from a single point of failure. Thus, they are distributed, transparent, immutable, and secure. Tokenised carbon offsets could convey relevant information about the project itself, and buyers could be sure that this information has not been tampered with. This increases trust in carbon credits. Of course, this mechanism would still rely on the original data being accurate, and hence it should ideally be combined with effective MRV.

Another key feature of blockchains is that they remove the need for a trusted intermediary. In the case of offsetting, this trusted intermediary is usually a company like Verra, which administers the Verified Carbon Standard. As these companies charge for their services, removing their intermediary role effectively removes an implicit tax on the price of purchasing and trading offsets. While reducing transaction costs is generally positive, one historic issue is that offsets do not command a high enough price to incentivise efficiently reaching climate goals. Carbon offsets should ideally be more expensive than the cost of making appropriate and feasible emissions reductions as organisations are usually the best agents for directly effecting change within their own practices, so making this strategy too cheap and easy could create perverse incentives. However, offsets also tend to be undervalued because they often overestimate the volume of emissions reductions for a number

\footnotetext{
73 Woodland Carbon Code. 2021. Woodland Carbon Code: Requirements for Voluntary Carbon Sequestration Projects. https://woodlandcarboncode.org.uk/images/PDFs/Woodland_Carbon_Code_V2.1_March_2021.pdf.

$74 \quad$ Asner, G. 2009. 'Tropical forest carbon assessment: integrating satellite and airborne mapping approaches' in Environmental Research Letters.
} 
of reasons including the risks explored in Section 4.2. If emissions reductions are more accurately measured, the market price of offsets could better reflect and mitigate these concerns.

Though blockchain applications such as cryptocurrencies are commonly criticised for their large energy usage, this is because older blockchains use the computationally inefficient and carbon-intensive 'proof-of-work' consensus mechanism. Newer blockchains use the much less energy-intensive 'proof-of-stake' consensus mechanism. ${ }^{75}$ For a $\$ 1,000$ carbon offset, the ratio of carbon reduced to carbon expended is 100 million to one when using a proof-of-stake blockchain. Any blockchain-based trading system should, therefore, use a proof-of-stake mechanism.

\subsection{Private sector measures}

Companies and other private sector organisations can have a large influence on offsetting integrity and strategy. Two key types of organisation are relevant here: organisations that verify and issue carbon credits that may then be bought as offsets, and organisations that may purchase offsets to reach net zero or meet other climate targets.

\subsubsection{Verification standards and trading plat- forms}

Organisations that verify and record emissions reductions to facilitate emissions trading are vital to voluntary carbon markets and play an important role in improving the integrity of offsetting using nature-based solutions. Large verification bodies already take many steps to mitigate the risks listed above by only allowing certain methods of carbon reduction or removal, requiring regular monitoring of projects, and maintaining transparent and detailed registries. ${ }^{76}$ These bodies are likely to continue to play an important role in improving the integrity of offsetting. By capitalising on emerging technologies and increased interest in emissions reduction and carbon removal projects, they can enhance their processes. This may include streamlining internal processes to reduce transaction costs, enhancing MRV requirements to allow for more regular and detailed monitoring, and approving innovative but proven nature-based solutions. These bodies should also work with public and private sector stakeholders on joint initiatives including linking regulated and voluntary markets.

In parallel to the continued operation of large incumbent standards, a number of smaller trading platforms and verifiers have emerged. Some of these platforms focus on specific solutions, whilst others utilise some of the emerging technologies discussed in Section 5.2 to offer cheaper or more efficient trading. ${ }^{77}$ These platforms may play an important role in incubating new methods and technologies before they see widespread deployment, though they should ensure that their standards are rigorous and address the risks discussed in this paper. Indeed, certain platforms use existing verification standards to approve their carbon credits or tokens.

Despite the growing number of verification processes and standards, the voluntary carbon market is still young and largely unregulated. To ensure accurate carbon offsets and protect against 'greenwashing', institutions that rate and regulate carbon credits may evolve, potentially akin to the highly developed rating of financial instruments such as bonds.

\subsubsection{Businesses with climate targets}

Businesses must ensure that their offsetting strategy is appropriate. An increasing number of businesses are setting ambitious climate change targets and have a wide range of options for carbon offsetting with no universal standards or guidelines. This means that understanding both when and how to offset their emissions is vital. The first step in this process is getting a clear picture of their current and historic emissions-including measuring 'Scope 3' emissions, those emissions associated

\footnotetext{
75 King, S. and Nadal, S. 2012. PPCoin: Peer-to-Peer Cryptocurrency with Proof of Stake. https://www.chainwhy.cc/upload/default/20180619/126a057fef926dc286accb372da46955.pdf.

76 Kollmuss, A., Zink, H. and Polycarp, C. 2008. Making Sense of the Voluntary Carbon Market: A Comparison of Carbon Offset Standards. https://www.globalcarbonproject.org/global/pdf/WWF_2008_A\%20comparison\%20of\%20C\%20offset\%20Standards.pdf.

77 See for example Nori and Moss. Earth, companies that trade soil carbon and forestry credits respectively using blockchain technology.
} 
with a company's supply chain that are not directly under its control, to the greatest extent possible. ${ }^{78}$ Next, they should devise a strategy that makes an honest and ambitious effort to reduce their emissions to the greatest extent possible. Before purchasing offsets, they might consider whether they can directly deploy technical or nature-based carbon removal methods in their own supply chains (insetting). In addition to these actions, businesses should use offsetting to account for any residual emissions and potentially purchase carbon credits to go beyond their net zero targets. Businesses could distinguish between different types of carbon credits when deciding which actions count towards net zero targets. For example, credits representing carbon removal projects might be used to offset emissions and count towards net zero targets, whereas avoided emissions credits, which are often more exposed to certain risks such as additionality and leakage, might be separate to, and therefore in addition to, a company's net zero strategy. Finally, when deciding how to offset their emissions businesses should consider the risks and opportunities presented in this report and choose a reliable verification body and trading platform.

Businesses should consider the social implications of how offsetting fits with their broader actions. This means both understanding the social implications of the nature-based projects that they are funding, but also considering how their offsetting strategy relates to their broader social responsibilities. In addition to taking the steps above, the private sector can play a key role in funding, supporting, and operationalising new initiatives that enhance offsetting through emerging technologies. However, businesses do need to have the right tools to make the best offsetting decisions possible within the next few years; there is probably not enough time to wait for a perfect global initiative for governing offsets. Campaigns such as the Science Based Targets Initiative ${ }^{79}$ and the Race to Zero ${ }^{80}$ may help businesses through this process whilst also offering reputational benefits. Experts and relevant climate-focussed organisations can help businesses understand offsetting so that they can make more informed choices. Ultimately, however, the private sector has a responsibility to devise ambitious but considered climate plans and turn these plans and targets into immediate action.

\section{Conclusion}

Nature-based solutions can play a key role in mitigating climate change and the carbon offset market is a growing source of funding for these solutions. The foregoing paper has discussed a number of important aspects and challenges with carbon offsetting using nature-based solutions to climate change. An array of individuals and institutions in both the public and private sectors, including the University of Cambridge, are working to understand and address these challenges. A multidisciplinary effort embracing innovative technology, effective governance and ambitious action could improve the collective understanding of when offsetting using nature-based solutions might be effective and how to best minimise the costs and maximise the benefits of this strategy.

Given the urgency of the climate crisis, it is important that organisations do not hesitate to act while long-term solutions are being devised. The discussions outlined in this paper may help guide organisations towards key considerations when devising an offsetting strategy. This would involve first deciding how and whether offsetting may best fit within their climate goals and strategy; and then determining how to ensure that any projects they decide to fund have high integrity. When combined with ambitious efforts to directly reduce emissions,

\footnotetext{
78 Greenhouse Gas Protocol. 2013. Technical Guidance for Calculating Scope 3 Emissions. https://ghgprotocol.org/sites/default/ files/standards/Scope3_Calculation_Guidance_O.pdf.

$79 \quad$ Science Based Targets Initiative. 2021. SBTI Web Site. https://sciencebasedtargets.org/.

80 UNFCCC. 2021. 'Race to Zero Campaign' web page. https://unfccc.int/climate-action/race-to-zero-campaign.
} 
smart offsetting offers businesses a chance to contribute to the global deployment of nature-based solutions to climate change.

In summary, offsetting using nature-based solutions has the potential to form a part of the large-scale and multifaceted fight against climate change, however effectively using this strategy requires careful consideration of the challenges discussed in this paper. The University of Cambridge, alongside many other organisations and institutions, is aiming to address these challenges through both its own internal offsetting strategy and projects that aim to improve the integrity of offsetting and nature-based solutions more broadly.

\section{Acknowledgements}

This paper was written by Nick Scott, Dr Shaun Fitzgerald, and Professor Srinivasan Keshav.

The content in this paper is based on discussions within a reading group that included Dr Matthew Agarwala, Professor Andrew Balmford, Joanna Chamberlain, Professor David Coomes, Professor Laura Diaz Anadon, Dr Rob Doubleday, Emily Farnworth, Harriet Hunnable, Professor Andreas Kontoleon, Professor lan Leslie, Professor John Pyle, Dr Ellen Quigley, Dr David Reiner, Professor Susan Owens, Dr Emily Shuckburgh, Dr Tom Swinfield, and Eliot Whittington.

Thanks also goes to Dr Ethan D. Aines, Harriet Harthan, Teresa Hartmann, Alasdair Neilson, and Amir Safaei for their contributions to this paper. 